\title{
Exploring connections between teacher interpersonal behaviour, student motivation and competency level in competence-based learning environments
}

\author{
Zainun Misbah $^{1,2} \cdot$ Judith Gulikers ${ }^{2} \cdot$ Wahyu Widhiarso ${ }^{3} \cdot$ Martin Mulder $^{2}$
}

Received: 30 December 2019 / Accepted: 11 October 2021 / Published online: 25 October 2021

(c) The Author(s) 2021

\begin{abstract}
Studies of connections between teacher behaviour and student outcomes are numerous, but those specifically addressing such connections in a competence-based vocational education setting are limited. For a sample of Indonesian students, this study examined the connection between two dimensions of teacher interpersonal behaviour (proximity and influence) and student competency levels, as well as whether or not these relations are mediated by students' intrinsic motivation. Additionally, it examined if these relations differed in learning environments with high versus low characteristics of competence-based education (HCBE vs. LCBE). Three questionnaires responded to by 506 first-year students were analysed using multigroups structural equation modelling. Teacher cooperative behaviour affected student motivation positively, and the influence was stronger in LCBE learning environments. Teacher controlling behaviour reduced student-perceived competency levels, with the reduction stronger in HCBE learning environments. Implications of the findings for teaching and learning in vocational education are discussed.
\end{abstract}

Keywords Competence-based vocational education · Competency level $\cdot$ Intrinsic motivation $\cdot$ Teacher interpersonal behaviour

\section{Introduction}

Over the past decades, numerous studies of connections between teacher behaviour and student outcomes have been conducted. These studies focus on cognitive outcome for a specific subject such as mathematics (den Brok, 2001; Goh \& Fraser, 1998; Lapointe et al., 2005; Maulana et al., 2012; Rawnsley, 1997), physics (Brekelmans, 1989), English

Zainun Misbah

zainun.misbah@kemdikbud.go.id

1 Directorate General of Teachers and Educational Personnel, Ministry of Education and Culture, Jakarta, Indonesia

2 Education and Learning Sciences, Wageningen University and Research Center, Wageningen, The Netherlands

3 Faculty of Psychology, Gadjah Mada University, Yogyakarta, Indonesia 
as a foreign language (Maulana et al., 2012; Wei et al., 2009), or on attitudinal outcomes such as attitude toward science, academic efficacy, and feeling confidence (den Brok et al., 2005; Fisher \& Rickards, 1998; Gupta \& Fisher, 2011; Kim et al., 2000; Martin \& RimmKaufman, 2015; Sivan \& Chan, 2013; van Petegem et al., 2008). The studies identified positive and negative relations between certain types of teacher behaviour and student outcomes. While a strong theoretical foundation and empirical evidence exist for relations between teacher behaviour and student outcomes, studies that connect teacher behaviour and student outcomes in competence-based vocational education (i.e., student competence development) are limited. Equipping students with the necessary competencies for future jobs is important and in line with the aim of vocational education to prepare students for better entering the marketplace. This study explored if and what kind of teacher behaviour facilitates students' competence development.

Competence-based education (CBE) is an educational philosophy and strategy which stresses the importance of teaching and learning integrated knowledge, skills and attitudes around core professional tasks. CBE is comparable to student-centered educational innovation in primary and secondary education that focuses on students' learning needs, their interests and ambitions, as well as their background (taken as starting point for the teaching process), instructional development and curriculum design, and self-regulated learning. CBE has a strong position in vocational education and training (VET) setting (Kouwenhoven et al., 2010). VET is offered at various levels and for all sectors of the economy, such as technology, health care, administration, and agriculture. It is at levels 4 to 7 of the European Qualifications Framework.

Competence-based education in vocational education (CBVE) aims to equip people with knowledge, know-how, skills and/or competences required in particular occupations or more broadly on the labour market. In CBVE, the role of teachers and students changes and results in different teacher-student interactions; the traditional role of a teacher as a knowledge transmitter is no longer sufficient. Teachers are expected to act more as coaches than instructors. They use less direct instruction by explaining theory and presenting solutions to problems (explanatory mode) and more authentic assignments, group work and assessment for learning and feedback. This stimulates active learning. Their role evolves from sage on the stage to guide by the side. The teacher provides more student support, based on the needs of students. Because currently the VET all over the world is changing towards competence-based, or outcome-based (Young, 2009), education (Billett, 2001; Wiegel et al., 2007), studying teacher-student interactions and their relations with student competencies is highly relevant for more evidence-based of CBVE (Lassnigg, 2017; Slavin, 2008).

CBVE aims at better preparing students for their future jobs and reducing the number of school leavers before graduation because of a lack of motivation (Wesselink, 2010). CBVE fosters student motivation by making education more authentic and representative of students' future jobs (Gulikers et al., 2009). In educational psychology literature, student motivation is one of the most important variables contributing to learning (e.g. Brophy, 1986; Deci \& Ryan, 2007) and student outcomes (e.g. Chen, 2001; Wijnia et al., 2011). Because teacher behaviour researchers have established connections between the way in which students perceive their teacher, their motivation (Maulana et al., 2011; Opdenakker et al., 2012), and their learning outcomes (den Brok, 2001), motivation should be taken into account when examining the relations between teacher interpersonal behaviour and student competency levels in the context of education that is more or less changing towards competence-based education. 
The context of our study was the Indonesian VET that is supposed to change towards more competence-based education (Misbah et al., 2019; MoNE, 2004). As indicated above, CBVE is characterised by a series of principles (Sturing et al., 2011; Wesselink et al., 2007), many of which have been studied (Mulder \& Winterton, 2017). One of the CBVE characteristics is that the role of teacher is changing toward a more coaching role (Sturing et al., 2011; Wesselink et al., 2007). Research into the role of teachers in CBVE has been undertaken, but to a limited amount only and it has been especially aimed at modelling and measuring teacher competence (Gulikers \& Mulder, 2013; Mulder, 2017). The extent to which VET schools have adopted the CBE principles (Sturing et al., 2011) still differs (Misbah et al., 2019). It is important, however, to know whether teachers in CBVE assume their new role and show interactive behaviour which augments competence development to support successful implementation of CBVE.

Our study examined connections between teacher behaviour and student perceived competency levels, as well as whether student intrinsic motivation mediates these connections. Teacher behaviour is often studied by using teacher interpersonal behaviour theory (Wubbels \& Brekelmans, 2005; Wubbels et al., 1985) that also was used in the present study. Additionally, this study compared these relations in VET schools that have already adopted the competence-based education principles (HCBE) with schools that are still characterised as having a low level of competence-based education (LCBE schools) (see Misbah et al., 2015, 2019; Sturing et al., 2011). Differences might be anticipated because CBE (compared with non-CBE) aims to stimulate competence development and motivation and entails, among other characteristics, different teacher and student roles (e.g. Sturing et al., 2011; Wesselink et al., 2007), and thus different teacher-student interactions. Results of this study potentially could give insights into effective teacher behaviour for fostering students' competence development. This study contributes to the body of knowledge on teacher interpersonal behaviour theory for different student outcome and challenges the emerging discussion on the motivational effect of teaching and learning in vocational education (Billett, 2003; Stroet et al., 2015; Wesselink et al., 2017). In the next sections, we elaborate the theoretical connections between the studied variables, the specific hypotheses, and a proposed model of the connections among those variables.

\section{Research on teacher interpersonal behaviour and student outcomes}

Researchers have investigated connections between teacher behaviour and student outcomes to seek information for improving teaching and learning in a classroom context (e.g. den Brok et al., 2004a; Fauth et al., 2019; Kyriakides et al., 2009; Skinner \& Belmont, 1993). Some studies used teacher interpersonal behaviour perspective (Wubbels \& Brekelmans, 2005; Wubbels et al., 1985) for examining teacher behaviour in various subjects, at different level of education, and in various countries. This perspective involves how teachers behave and interact with their students in a classroom using the model of interpersonal teacher behaviour (MITB), which maps teacher behaviour on the two dimensions of 'proximity' and 'influence'. Proximity refers to the degree of teachers' cooperative/friendly behaviour to students, while influence represents the degree of teachers' control/dominance shown to students (Maulana et al., 2012).

The teacher interpersonal behaviour perspective has contributed to explaining the connections between teacher behaviour and student outcomes. For example, den Brok et al. (2004a) reviewed associations between perceptions of influence and proximity and student outcomes, showing that teachers' proximity and influence affect students' 
cognitive as well as attitudinal outcomes. Brekelmans et al. (2002) found that the influence dimension had a positive association with student outcomes on a physics test; the more that students perceived their teachers as controlling, the higher students scored on physics tests. Other studies showed that the proximity dimension consistently connects with students' attitudinal outcomes such as pleasure, confidence, and efforts in mastering subjects. For example, Telli et al. (2007) showed, using regression analysis, that proximity was significantly related to more student enjoyment and interest in science in Turkish science classes. In the Dutch education setting, den Brok et al. (2004b) showed, using structural equation modelling, that better contact and more closeness between teachers and students (i.e., higher scores on proximity) resulted in higher student motivation. A study in India showed that both influence and proximity dimensions were positively related with attitudinal outcomes for secondary education (den Brok et al., 2005). In line with this, Fisher and Rickards (1998) stated that cooperative and somewhat dominant teacher behaviour contributes to favourable student attitudes in mathematics classes in Australia. Maulana et al. (2011) asserted that, in Indonesian high schools, influence and proximity correlate positively with student motivation. In addition, van Uden et al. (2014) stated that, when students in Dutch vocational schools perceived their teachers as having high scores on the two dimensions, they reported higher learning engagement. Both proximity and influence positively contributed to students' engagement with proximity proving more important for engagement than influence. In short, many studies have shown or suggested connections between teacher behaviour and student learning outcomes. A higher score on both the influence and proximity dimension is found to be more or less connected to a range of cognitive or attitudinal learning outcomes.

These kinds of relationships between teacher interpersonal behaviour and student outcomes pursued in CBVE have not been studied yet. CBVE aims at the different student outcome of competency instead of mainly knowledge development. Competency is "a coherent cluster of knowledge, skills and attitudes which can be utilised in real performance contexts" (Mulder, 2014, p. 111). Competency includes not only functional and behavioural requirements for functioning in a profession, but also more complex cognitive abilities and social abilities for functioning as a person (Le Deist \& Winterton, 2005). Although some studies had discussed competency level as a student outcome for vocational education (e.g. Khaled et al., 2014; Kyndt et al., 2014), research that specifically connected this outcome with teacher behaviour can hardly be found. Thus, the connections between teacher behaviour and student competency level is not yet clear.

As well as aiming at new learning outcomes, CBVE aims to stimulate different kinds of teacher and student roles (e.g. Sturing et al., 2011) that result in different student-teacher interactions. In CBVE, students are expected to become more active, autonomous, and selfdirective, while teachers are expected to be more of a coach of student learning than an expert conveying knowledge to students. In this context, teacher interpersonal behaviour might be different or differently effective than in a more-traditional types of education that have mostly been the context for current research into teacher interpersonal behaviour.

Research in the teacher interpersonal behaviour area also shows that the connection between teacher behaviour and student outcome is not always straightforward. In some studies, 'unwanted' teacher behaviour such as dissatisfied and admonishing behaviour was related to lower performance, but 'wanted' teacher behaviour such as friendly and understanding behaviour was related to higher performance (den Brok et al., 2004b; Rawnsley, 1997). In other studies, the relation between proximity and cognitive outcomes is not linear, but curvilinear (i.e. lower perceptions of proximity go with low outcomes, but intermediate 
and higher values are associated with higher performance until a certain ceiling of optimal proximity has been reached (den Brok, 2001; den Brok et al., 2004a). Thus, it is likely that there are some mediating variables involved. This study examined the mediating role of intrinsic motivation.

\section{Learning motivation}

Research has demonstrated that student motivation plays a key role in student learning (e.g. Deci \& Ryan, 2007; Skinner \& Belmont, 1993; Wijnia, 2020). Student motivation depends, at least partly, on the quality of a teacher's interpersonal motivating style (Reeve \& Jang, 2006; Reeve et al., 1999). Teacher interpersonal behaviour research also shows that how students perceive their teacher's behaviour influenced student motivation (e.g. den Brok et al., 2004a; Fauth et al., 2019; Hein, 2012; Maulana et al., 2011; Opdenakker et al., 2012). Motivation to learn, in turn, makes a significant contribution to student learning and outcomes. Motivated students tend to have better student performance (Brophy, 1986; Cerasoli et al., 2014; Chen, 2001). Also, in CBVE studies, student motivation is an important variable. The idea is that CBVE is more motivating for students than traditional types of education because it shows them the relevance of what they are learning for their future world of work (e.g. Biemans et al., 2004). Several studies showed that the relationship between teacher behaviour and student outcomes is mediated by learning activities and motivation (e.g. Ahmed et al., 2010; Shuell, 1996). Our study examined motivation as a mediator for the connections between teacher interpersonal behaviour and student competency levels, particularly in a CBVE learning environment context.

To operationalise students' learning motivation, this study utilised the idea of Ryan and Deci (2000), who distinguished intrinsic and extrinsic types of motivation. They defined intrinsic motivation as doing something because it is inherently interesting or enjoyable, while extrinsic motivation refers to doing something because it leads to a separable outcome (Ryan \& Deci, 2000; p. 55). This current study investigated motivation in terms of student intrinsic motivation because intrinsic motivation has a higher and significant association with the two dimensions of teacher interpersonal behaviour than extrinsic motivation (Maulana et al., 2012) and is a consistent predictor of student achievement across different school contexts and different cultures (Taylor et al., 2014). Furthermore, intrinsically-motivated students are consistently found to achieve better outcomes (Skinner \& Belmont, 1993).

\section{Research questions}

CBVE strives for different learning outcomes (i.e. competencies relevant for the labour market). Moreover, a CBVE learning environment is supposed to be more motivating and representative of the future world of work by developing more self-steering and lifelong learners. These three core ideas behind CBVE require different roles for students and teachers that are likely to result in different students-teacher interactions. The teacher interpersonal behaviour perspective promises a useful handle for investigating effective teacher behaviour for fostering student competencies and motivation, particularly in a competencebased vocational education setting. While existing teacher interpersonal behaviour studies cannot directly be transferred to the CBVE context, teacher interpersonal behaviour in relation to new learning outcomes (i.e. competencies) deserves explicit attention in empirical studies. 
Competence-based education had been adopted and implemented in Indonesian vocational schools to various stages. Some schools have largely adopted competence-based education principles in practice, while others are still working on adopting those principles in their school practices (Misbah et al., 2019; Sturing et al., 2011). Examining the connections among teacher interpersonal behaviour, student motivation, and competency level in learning environments with a high versus low level of competence-based learning is important because this will add to the existing body of knowledge of interpersonal behaviour theory and challenge the emerging discussion on teaching and learning in competence-based vocational education (Billett, 2003). Therefore, the research questions of this study were as follows.

1. Are perceived teacher interpersonal behaviour, intrinsic motivation and students' competency level connected in Indonesian vocational schools?

2. Do the two dimensions of teacher interpersonal behaviour influence students' competency levels?

3. If the relations do exist, does student motivation mediate the connection between teacher interpersonal behaviour and student competency levels?

4. Do the connections differ in high versus low CBVE schools in terms of structure and strength?

To answer these questions, the current study used structural equation modelling to characterise the relationship between the independent variables of the two dimensions of teacher interpersonal behaviour (proximity and influence; Wubbels et al., 1985), the mediating or intermediate variable of intrinsic motivation (Ryan \& Deci, 2000), and the four dependent variables consisting of the four competencies relevant in the context of our study (MoMT, 2009). Because the literature suggests that teachers being higher on the influence and proximity dimension is linked with better cognitive or attitudinal outcomes among students, we hypothesised that perceived teacher interpersonal behaviour also influences students' competency levels (H1). More specifically, we hypothesise that students who perceive their teachers as more influential (i.e. more dominant, more in control) also report higher scores on their competencies (H1a) and students who perceive their teachers as more collaborative/friendly (i.e. higher score on the proximity dimension) report higher competency levels as well (H1b).

Because a range of previous studies has shown positive relationships between two dimensions of teacher interpersonal behaviour and student intrinsic motivation, we hypothesise that there is also a positive relation between teacher behaviour and student intrinsic motivation in this study in the context of Indonesian VET (H2).

With respect to the relationship between student motivation and student outcomes in terms of competencies, both theoretical and empirical arguments can be found. In competence-based education, it is expected (or at least it is the purpose of changing toward competence-based education) that students get more motivated, because of the educational approach, and in turn reach higher levels of competence (e.g. Wesselink, 2010). Thus, it is hypothesised that higher intrinsic motivation relates to higher learning outcomes, including students' perceived competency levels (H3). Because studies have shown that teacher interpersonal behaviour influenced student intrinsic motivation and later students' outcomes, we hypothesised that student intrinsic motivation mediates the connections between teacher interpersonal behaviour and student perceived competency levels (H4). 
As described earlier, this study involved two different learning environments (i.e., HCBE vs. LCBE). Because a HCBE learning environment has different characteristics from a LCBE environment (e.g. more self-directed learning, less-teacher control, more authentic learning), the connections between teacher interpersonal behaviour and student competency levels is likely to be different in the HCBE versus LCBE contexts (H5). In a study relating competence-based learning environment to student intrinsic motivation, Misbah et al. (2015) found that students from schools with more characteristics of CBE (HCBE) scored higher on intrinsic motivation than students from schools with less characteristics of $\mathrm{CBE}$ (LCBE). Also, students' intrinsic motivation was more-closely associated with proximity than influence, with associations being stronger in LCBE than in HCBE learning environments. Therefore, it can be argued that the connections between teacher behaviour, intrinsic motivation and student outcomes differ in a HCBE and in a LCBE context (H6).

The variables mentioned-above and their theory-based hypothesised relationships together make up the hypothesised model shown in the Fig. 1.

\section{Methodology}

\section{Participants}

This study involved 506 students in their first year (grade tenth) of agricultural vocational schools. They were from 11 schools in three provinces in Indonesia. These schools were typified as either high or low competence-based education (HCBE or LCBE) based their 'competentiveness score', which is the degree to which the ten characteristics of CBVE as described by Sturing et al. (2011) are present within their educational program. The characteristics included, for example, authentic learning, self-directedness, and teacher roles (Sturing et al., 2011; Wesselink et al., 2007). School principals, teachers, and students rated the extent to which the CBVE characteristics were found in their study program, leading to

$\begin{array}{lll}\begin{array}{l}\text { Independent } \\ \text { variables }\end{array} & \begin{array}{l}\text { Intermediate } \\ \text { variable }\end{array} & \text { Dependent variables }\end{array}$

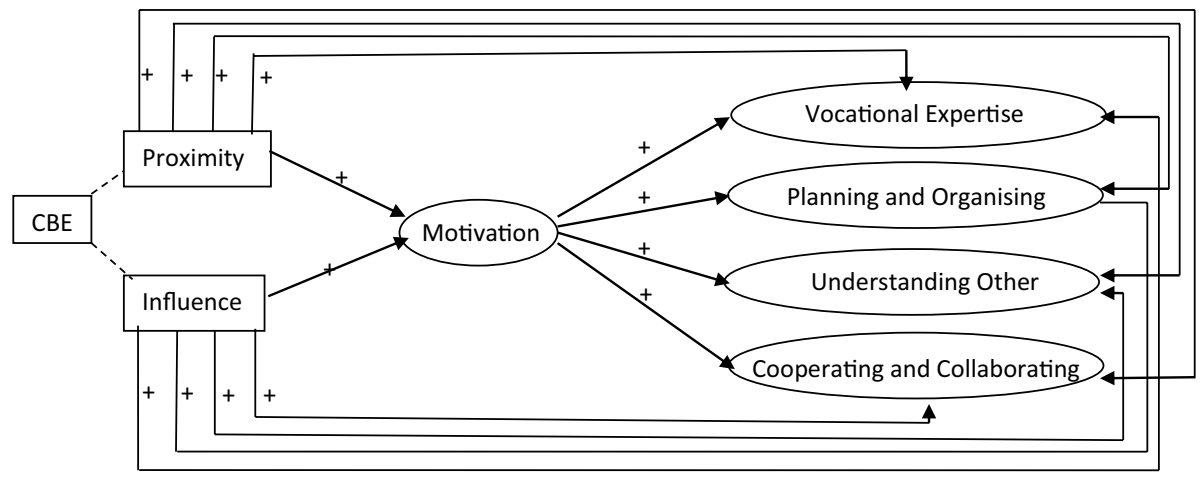

Fig. 1 Hypothesised model of teacher interpersonal behaviour, motivation and competency levels 
a competentiveness score for each study program ranging from 1 (lowest) to 5 (highest) (see Misbah et al., 2019).

From the 11 schools, five schools scored on or below 2 for their competentiveness (categorised as LCBE) and six schools scored around 4 (categorised as HCBE group). In total, 322 students taught by 17 teachers followed a HCBE program and 184 students taught by 15 teachers worked in a LCBE setting participated. All students undertook a food processing technology study program covering the same content in all schools (based on a national curriculum), and their ages ranged from 14 to 18 years old $(\mathrm{M}=16.01, \mathrm{SD}=0.65)$ with $61 \%$ of them being female.

\section{Materials}

\section{Perceived teacher interpersonal behaviour}

The validated Indonesian Questionnaire on Teacher Interaction (QTI) (Maulana et al., 2011) assessed students' perceptions of their teachers' interpersonal behaviour. The QTI consists of 54 items in a five-point Likert scale ranging from (1) strongly disagree to (5) strongly agree, and assesses the two dimensions of influence and proximity. Influence refers to the degree to which a teacher controls communication in the classroom (e.g. "This teacher is strict"). Proximity refers to the degree to which a teacher cooperates with students (e.g. "This teacher is someone we can depend on"). Previous studies have reported the validity and reliability of the QTI in the Indonesian context (e.g. Maulana et al., 2012; Misbah et al., 2015). In our study, we calculated scores for proximity and influence using the procedure of Wei et al. (2009). Following the idea of van Uden et al. (2014), this study treated the scores as observable scores and used them as independent variables in the structural model.

\section{Student intrinsic motivation}

Students' intrinsic motivation was measured using the Intrinsic Motivation Inventory (IMI) of Deci and Ryan (2007). Although the IMI provides five subscales for intrinsic motivation, the present study used only the subscale of interest/enjoyment because this was considered the self-report measure of intrinsic motivation per se (Deci \& Ryan, 2007). This subscale consists of six items on a 7-point Likert scale ranging from (1) not at all true to (7) very true (e.g. "I enjoyed the subject taught by this teacher very much"); Cronbach's alpha reliability in this study population was 0.78 . The intrinsic motivation score was used as an intermediate variable in the structural model.

\section{Competency level}

In this study, students' competency levels were measured using the validated Competence Development Measurement Instrument (CDMI) adapted the work of Khaled et al. (2014) and the Indonesian Qualification Framework for food processing and technology sector (MoMT, 2009). A previous study by Khaled et al. (2014) reported the validity and reliability of CDMI and its indicators. For this present study, the CDMI assessed four competencies relevant in the context of this study: vocational expertise (e.g. "I have much knowledge on food processing"), to plan and organise (e.g. "During the preparation of an assignment, 
I first consider which results I want to achieve"), to show attention and understanding others (e.g. "I carefully listen to what other people say"), and to collaborate and discuss (e.g. "During group meetings, I give valuable contributions to the final result"). Each competency was measured by 4 to 6 performance indicators (i.e. items), resulting in 21 items in total. Students scored each item on a scale of 1 to 10, with 1 standing for low achievement and 10 standing for high achievement. We used the four competencies as the dependent variables in the structural model.

\section{Procedure}

Students responded to the three instruments in the middle of the first year of study. The first researcher was always present in the class during data collection to answer any possible questions from students. To minimise bias response, teachers were not present in the class during data collection and the researcher was informed that teachers would not see students' individual responses. The study protocol was approved by the Educational Authorities. School principals and teachers gave permission for the researcher to access the classes in the sample.

\section{Data analyses}

We initially conducted preliminary analysis to obtain the mean scores, standard deviation, and correlation coefficients among variables. A measurement model was tested to check the structure of the instruments before testing our hypothesis. This included the latent constructs of the four competencies and the intrinsic motivation variable and assessed whether the indicators represented the constructs properly by means of confirmatory factor analysis. Measure of fit reported included chi-square $\left(\chi^{2}\right)$, the comparative fit index (CFI), the nonnormed fit index or Tucker-Lewis Index (TLI), the root-mean square error of approximation (RMSEA), the standardised root-mean square residual (SRMR), and Gamma Hat. CFI values of greater than or equal to 0.95 , TLI values larger than or equal to 0.90, RMSEA values smaller than 0.08, SRMR and Gamma Hat values were all considered to be indicatives of good fit (Bentler, 1990; Bentler \& Bonnet, 1980; Bollen, 1989). We also found acceptable levels of fit for the normed chi-square values (i.e. chi-square divided by degrees of freedom).

To explore possible misfits of the model, we examined the modification indexes (MI) for the regression weights. High MI scores can indicate that an important link is missing in the model. The missing links then were connected in our model to achieved a satisfactory measurement model cautiously. Once the satisfactory model was obtained, we used structural equation modelling (SEM) to assess the extent to which the hypothesised model adequately fitted or described the empirical data. The structural model included the hypothesised relationships among the dimensions of teacher interpersonal behaviour and the latent constructs (i.e., intrinsic motivation and level of competencies).

A significant link between the independent variables (i.e. proximity and influence) and the presumed mediator (i.e. intrinsic motivation), between the mediator and the dependent variables (i.e. the levels of four competencies), and between the independent and dependent variables were examined to test intrinsic motivation as a mediating variable. If full mediation is present, this latter effect is rendered nonsignificant when the mediator is entered into the model, and also the test of the indirect effect must be significant. If the effect of 
the independent variable on dependent variable is still significant even after the mediator is added, this can be considered as partial mediation (van Ryzin, 2011).

To examine if the relationships in the model for HCBE and LCBE groups were equal or different, multi-group SEM was used. Multigroup model analyses can provide a better and more-differentiated picture of associations between teacher interpersonal behaviour and student outcomes than traditional regression data analyses (den Brok et al., 2010). Group differences were assessed by comparing a fully-constrained model (i.e. all path coefficients equal across group) versus an unconstrained/baseline model (i.e. the path coefficients were not constrained across the group) using the $\chi^{2}$ difference test. If the chi-square difference was higher than the critical ratio and proved significant, it indicated a difference between HCBE and LCBE groups (Byrne, 2016). Then, the differences for each path coefficients were analysed by sequentially comparing the $\chi^{2}$ difference test between the baseline model and a particular constrained path model. The data analyses were conducted using Amos version 21 (Arbuckle, 2012).

\section{Results}

This section presents descriptive statistics for and correlations between the studied variables followed by the measurement model and the structural equation modeling for testing our hypothesis. Next, results of the comparison between the HCBE and LCBE groups are presented.

\section{Correlational analyses and descriptive statistics}

Means, standard deviations, and correlation coefficients among the study variables are presented in Table 1. As expected, influence and proximity correlated positively with student intrinsic motivation, as well as with the level of four competencies. Lastly, intrinsic motivation significantly correlated with all four competencies. These associations provide a foundation for testing intrinsic motivation as a mediating variable influencing the link between teacher interpersonal behaviour and student competency levels.

\section{Assessment of measurement model}

Confirmatory factor analysis revealed that the initial measurement model of the four competencies of Competence Development Measurement Instrument (CDMI) and the intrinsic motivation scale of Intrinsic Motivation Inventory (IMI) showed acceptable model fit, $\chi^{2}(290)=944.869 ; \mathrm{CFI}=0.943 ; \mathrm{TLI}=0.931 ; \mathrm{RMSEA}=0.048 ; \mathrm{SRMR}=0.039$, Gamma Hat $=0.932$ and $\chi^{2} / \mathrm{df}=3.258$. However, the factor loading for two items in the IMI scale and one item in the competency instrument about showing attention and understanding others were problematic (below 0.40) (Tabachnick \& Fidell, 2007). Those problematic items were deleted as long as they did not affect the meaning of the constructs. After deletion, factor loading improved, ranging from 0.45 to 0.85 , and the items' critical ratio values exceed $9.922(p<0.01)$ (see Table 2 in Appendix 1). The construct of 'understanding other' remained a little problematic because the square root of AVE was smaller than 
Table 1 Assessment of measurement model

\begin{tabular}{|c|c|c|c|c|c|}
\hline Constructs and Item & $\begin{array}{l}\text { Standardized } \\
\text { factor loading }\end{array}$ & Standard error & Critical ratio & Cronbach alpha & AVE \\
\hline Intrinsic motivation & & & & 0.82 & 0.55 \\
\hline im1 & 0.822 & 0.083 & 19.101 & & \\
\hline $\operatorname{im} 2$ & 0.873 & 0.082 & 19.177 & & \\
\hline im6 & 0.638 & 0.073 & 16.601 & & \\
\hline $\operatorname{im} 20$ & 0.606 & & & & \\
\hline Vocational expertise & & & & 0.85 & 0.56 \\
\hline ve1 & 0.776 & & & & \\
\hline ve2 & 0.844 & 0.039 & 28.534 & & \\
\hline ve3 & 0.690 & 0.050 & 20.284 & & \\
\hline ve4 & 0.741 & 0.050 & 21.697 & & \\
\hline ve5 & 0.662 & 0.061 & 19.536 & & \\
\hline Collaboration & & & & 0.87 & 0.55 \\
\hline $\operatorname{cd} 5$ & 0.658 & & & & \\
\hline cd6 & 0.708 & 0.049 & 19.962 & & \\
\hline $\operatorname{cd} 7$ & 0.723 & 0.052 & 20.322 & & \\
\hline $\operatorname{cd} 8$ & 0.856 & 0.052 & 21.433 & & \\
\hline $\operatorname{cd} 9$ & 0.745 & 0.052 & 17.922 & & \\
\hline Planning and organising & & & & 0.84 & $0.48 *$ \\
\hline po1 & 0.719 & & & & \\
\hline po2 & 0.704 & 0.038 & 23.487 & & \\
\hline po3 & 0.649 & 0.057 & 15.953 & & \\
\hline po4 & 0.738 & 0.055 & 18.687 & & \\
\hline po5 & 0.657 & 0.055 & 17.119 & & \\
\hline Understanding others & & & & 0.78 & $\left.0.46^{*}\right)$ \\
\hline u1 & 0.566 & & & & \\
\hline u3 & 0.641 & 0.067 & 16.087 & & \\
\hline $\mathrm{u} 4$ & 0.741 & 0.075 & 13.928 & & \\
\hline u5 & 0.761 & 0.081 & 15.754 & & \\
\hline
\end{tabular}

*Recommended guideline of AVE is $>0.50$, but it is still acceptable because the internal consistency (Cronbach alpha) is $>0.60$ (Fornell \& Larker 1981)

the correlation with 'vocational expertise' and 'planning and organizing'. However, it was still acceptable because the Cronbach alpha coefficient was larger than 0.60 (Fornell \& Larker 1981) (see Table 3 in Appendix 2). Model fit improved as well, $\chi^{2}(242)=843.190$; $\mathrm{CFI}=0.946 ; \mathrm{TLI}=0.933 ; \mathrm{RMSEA}=0.050, \mathrm{SRMR}=0.039$, Gamma Hat $=0.935$ and $\chi^{2}$ / $\mathrm{df}=3.484$.

\section{Structural model}

Subsequent to establishment of acceptable measurement model fit, hypothesised regression paths connections in a structural equation modeling (see Fig. 1) was conducted using the maximum likelihood method. The structural model indicated good fit, $\chi^{2}$ 


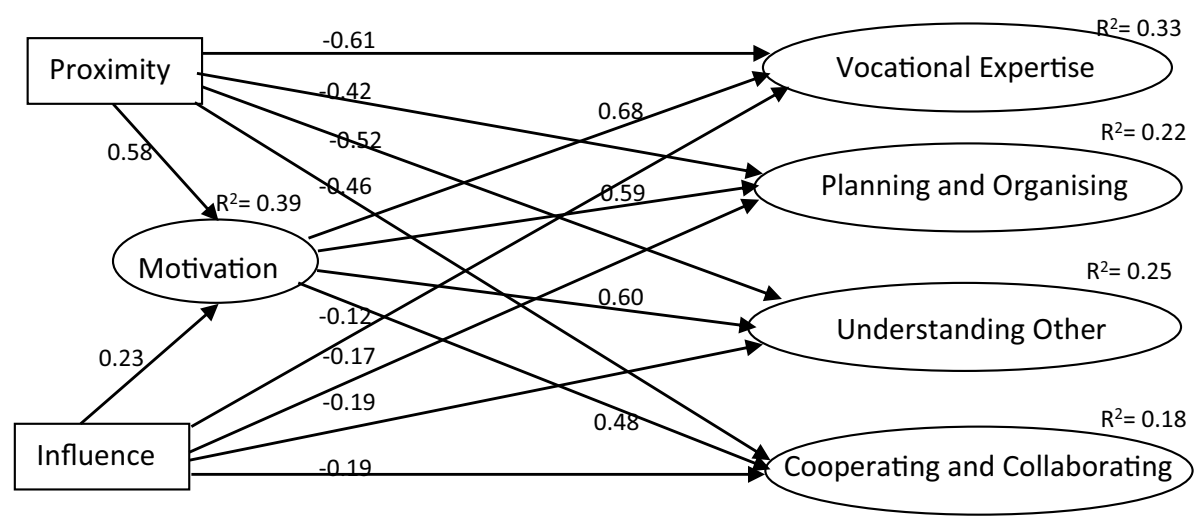

Fig. 2 Structural model paths and standardised regression weights of paths

$(263)=871.219 ; \mathrm{CFI}=0.945 ; \mathrm{TLI}=0.932 ; \mathrm{RMSEA}=0.049 ; \mathrm{SRMR}=0.039 ;$ Gamma Hat $=0.936 ; \chi^{2} / \mathrm{df}=3.313$. Statistically-significant coefficient paths $(p<0.05)$ in our proposed model are shown in Fig. 2. This model accounted for a moderate proportion of variance in intrinsic motivation $\left(R^{2}=0.39\right)$ and the four competencies: vocational expertise $\left(R^{2}=0.33\right)$, planning and organising $\left(R^{2}=0.22\right)$, understanding other $\left(R^{2}=0.25\right)$, and cooperating and collaborating $\left(R^{2}=0.18\right)$.

Figure 2 shows that both dimensions of teacher behaviour were significantly associated with student intrinsic motivation $(\beta=0.87, p<0.05$ for proximity and $\beta=0.41, p<0.05$ for influence). This means that teachers who were perceived as more collaborative/friendly (Proximity) and/or more dominant (Influence) positively stimulated intrinsic motivation, which supports $\mathrm{H} 2$.

With respect to $\mathrm{H} 1, \mathrm{H} 1 \mathrm{a}$ and $\mathrm{H} 1 \mathrm{~b}$, significant relations were found, but in an unexpected direction. Both proximity and influence had negative associations with the four competencies, suggesting that the more that the teacher controlled students, the lower students rated their competency levels. This also held for proximity, meaning that, when student perceived their teacher as more cooperative, they reported lower perceived competency levels. In addition, the effect of proximity was stronger than influence. Student intrinsic motivation was associated positively with the levels of all four competencies to varying degree. This suggested that students who were more intrinsically motivated reported higher levels of competencies, supporting $\mathrm{H} 3$.

To test the mediating effect of intrinsic motivation, the direct relations of proximity and influence with the four competencies (the direct model) were compared with the relations in our hypothesis model. The direct model showed satisfactory fit indices, $\chi^{2}$ $(125)=500.526$; $\mathrm{CFI}=0.955 ; \mathrm{TLI}=0.939 ; \mathrm{RMSEA}=0.054 ; \mathrm{CMIN} / \mathrm{df}=4.004$, Gamma Hat $=0.952, \mathrm{SRMR}=0.032$ and the paths between proximity and influence on the four competencies were all significant. Table 2 presents the coefficient paths of direct effects with and without a mediating variable and indirect effects of our hypothesised model.

As can be seen from Table 4, all paths in the direct model were significant, indicating that the influence and proximity dimensions had significant direct effects on the four competencies, with and without intrinsic motivation as a mediating variable. A significant indirect effect, shown by confidence intervals that did not contain zero, indicated the significance of intrinsic motivation as a mediating variable. Because the indirect effects were 
significant, and the direct effects remained significant when student intrinsic motivation was included as a mediator in the model, it can be concluded that intrinsic motivation partially mediated the connection between proximity and influence and student competency levels (H4). However, the direction of the direct effects changed to negative when intrinsic motivation was included, indicating that intrinsic motivation was an inconsistent mediator variable (MacKinnon et al., 2007).

\section{HCBE versus LCBE}

Research question 2 involves whether the hypothesised connections between teacher interpersonal behaviour, intrinsic motivation and competency levels differ in a HCBE versus a LCBE context. For this purpose, multi-group confirmatory factor analyses were first conducted to test the measurement model for the four competencies and the intrinsic motivation scale for both groups. The invariance test showed the latent scores on competency levels and intrinsic motivation differed significantly between the groups, but that these differences did not adversely affect the proposed measurement model. To test whether the structural model differed in a HCBE versus LCBE context, evaluation of the SEM model as shown in Fig. 2 was conducted for each group by testing the chi-square difference between the baseline/constrained model and the fully-constrained model (equal across groups). The goodness-of-fit statistics for the two-group structural models are presented at Table 5. The fit indices for both the unconstrained and fully-constrained model suggested satisfactory fit to the data. The chi-square difference $\left(\Delta \chi^{2}=69.1 ; p<0.05\right)$ was statistically significant, which suggests that the groups were different.

Given the significant difference for HCBE versus LCBE groups, we tested the path coefficients for each group. Table 6 presents the two group model estimates. As can be seen from Table 6, two paths were significantly different. The negative relationship between influence and competency planning and organising were differ between HCBE and LCBE groups, with the effect stronger in $\mathrm{HCBE}$ than in $\mathrm{LCBE}\left(\beta_{\mathrm{HCBE}}=-1.424, \beta_{\mathrm{LCBE}}=-1.189\right)$. This means that, when HCBE students perceived their teacher as more controlling, there was a stronger negative impact on their planning and organising competency level compared with a controlling teacher in a LCBE context. The effect of proximity on student motivation was also different between HCBE and LCBE $\left(\Delta \chi^{2}=20.255, p<0.05\right)$, with the effect of proximity being stronger in LCBE than in $\operatorname{HCBE}\left(\beta_{\mathrm{HCBE}}=0.867, \beta_{\mathrm{LCBE}}=0.874\right)$. Thus, in an LCBE context, teachers who were perceived as closer to students, more strongly impacted students' motivation which, in turn, affected student perceived competency levels.

\section{Conclusions and discussion}

Competence-based vocational education focuses on preparing student for success in the world of work by placing greater focus on competencies rather than merely on cognitive outcomes. In the present study, we investigated connections between teacher interpersonal behaviour, student motivation, and perceived competency levels among a sample of students from schools with high and low levels of characteristics of competence-based education in Indonesian vocational schools. Structural Equation Modelling analyses showed that students' perceptions of teacher interpersonal behaviour influenced how they rate their 
competency levels, mediated partially by student intrinsic motivation. Teacher interpersonal behaviour deserves more attention, in both practice and research, in an educational innovation in which the learning environment requires changing roles of teachers and students as in competence-based vocational education.

An HCBE and an LCBE context differed in the strength of connections between teacher behaviour, students' intrinsic motivation, and perceived competency levels. A more-controlling teacher in an HCBE context had a stronger negative influence on students' planning and organising competency level than a controlling teacher in an LCBE context. In $\mathrm{CBE}$ theory, teachers are expected to be less-controlling when facilitating the student learning process. More control is given to students because this is theorised to be important for letting students develop their own competencies. When a teacher is more controlling, this in conflict with what is actually required in competence-based education. This might result in confusion or conflict between student and teacher roles. Who is in charge? Who is deciding on the planning? The student or the teacher? This kind of confusion can be a possible explanation for the negative impact of teacher controlling behaviour on students' competency levels.

Differences between HCBE and LCBE groups also were found for connections between teacher proximity and student motivation. In an LCBE context, teachers who were perceived as closer to students, more positively impacted students' motivation which, in turn, affected student competency levels. This might also be attributable to the characteristics of the $\mathrm{CBE}$ learning environment. In $\mathrm{CBE}$, students are expected to be more autonomous and self-steering and, thus, less reliant on their teachers. In CBE, this increased autonomy for students is also expected to be intrinsically motivating for them. Students in LCBE are likely to be more reliant on their teachers and, as a result, appreciate more closeness with their teachers. Thus, this finding might suggest that principles of competence-based education actually were implemented as intended in the studied classrooms, in the sense that the HCBE participants were less dependent on their teachers.

The finding that teacher proximity was more influential on student outcomes (competencies) than controlling teacher behaviour corresponds to previous studies of learning environments and teacher interpersonal behaviour (e.g. Hughes \& Cao, 2018; van Uden et al., 2014). In our research, findings for the LCBE group were more comparable with the results of previous studies, while the HCBE learning environment led to different patterns of results. A possible explanation is that the LCBE learning environment is a more 'traditional learning environment' comparable to many classrooms in other studies of teacher interpersonal behaviour, while the HCBE learning environment is a new (different kind of) classroom that indeed aims at different teacher and student roles and different interactions and, as a result, also leads to different relations between teacher behaviour and student learning motivation. So, this study interestingly shows that connections between teacher interpersonal behaviour and student learning outcome are indeed different in these new contexts.

Another important result in this study is the mediational role of intrinsic motivation in linking teacher behaviour and student outcomes. Our study shows that student intrinsic motivation partially mediated the connection between teacher behaviour and student perceived competency levels. That intrinsic motivation becomes an inconsistent mediator suggests that the positive influence of teacher behaviour on competency level is an indirect effect via motivation, while a direct effect of teacher interpersonal behaviour on competency level is negative. This result suggests that effective teacher behaviour for fostering student competence development involves continuously fostering student intrinsic motivation. 
The findings of this study have some implications for teaching and learning in vocational education and can be used as a policy input for improvement of vocational education, certainly in Indonesia. VET students appear most vulnerable in terms of quitting their study before graduation partly because of a lack of motivation (van Uden et al., 2014). This study supports previous research suggesting that students' learning environment perceptions, including the teachers in it, can certainly make a difference to motivation (e.g. Hughes \& Cao, 2018; Urdan \& Schoenfelder, 2006). Because teachers are the most-important players in creating the actually implemented learning environment, teacher behaviour deserves more attention in teacher training programmes and educational innovations. The effect of teacher behaviour on student motivation can be positive or negative (Gorham and Christopel 1992) and the kind of teacher behaviour that is most appreciated by students differs in more-traditional (i.e. LCBE) versus HCBE contexts. With the appropriate amount of teacher control, students might feel secure and cared for, but too much controlling behaviour results in students feeling incapable, which result in decreasing student intrinsic motivation. This seems even more true in the CBE contexts where the whole education context places emphasis on student autonomy compared with teacher control. As Indonesian vocational education is changing towards competence-based education (Misbah et al., 2019; Nuh, 2013), successful teacher behaviour for fostering motivation and competence development should be seriously considered.

Some limitations in this study need to be considered for future research. The study's cross-sectional design prevents drawing conclusions about the effects of teacher behaviour on student competence development over time. While this study provides a theoretical model for such connection, a longitudinal study is needed to gain more insights into the complex process of students learning and its outcomes in vocational education. In addition, research using longitudinal designs has shown that students' perceptions of teacher behaviour changes over time and that student motivation decreases within a year (Maulana et al., 2012; Opdenakker et al., 2012). Thus, examining relationships between variables in a longitudinal way would give additional knowledge about the complexity of the connection between teacher behaviour, student motivation, and competence development in the long run. Secondly, the data in this study were collected only through self-report measures that could be a threat to internal validity (Ward et al., 2002). While previous studies showed that student self-perception is important (e.g. Khaled et al., 2014), multiple methods for assessment could be used to reduce the impact of subjectivity in future research. Another limitation is that the participants in our study sample were exclusively from the Indonesian culture, which might limit the generalisability of findings. Similar studies among different cultures, including comparing more-individualistic cultures (i.e. many Western countries) with more-collectivistic cultures (i.e. Indonesia), need to be conducted to gain better insights into connections between teacher behaviour, student motivation, and perceived competency levels.

Despite the limitations above, this study is important in providing an empirical support for the need for more attention to teacher behaviour in educational innovations in vocational education settings, particularly when the innovation involves drastically changing teacher and student roles, as in competence-based education. This study challenges the existing theory of teacher interpersonal behaviour by expanding the effect for different student outcomes (i.e., competency level). To the best of our knowledge, this is the first study connecting teacher behaviour to student perceived competency level. Therefore, our model can serve as a starting point for further research on effective teacher behaviour for students' competence development using a longitudinal study design. 


\section{Appendix 1}

See Table 2.

Table 2 Discriminant validity test: square root of AVE and inter-construct correlation

\begin{tabular}{llllll}
\hline Construct & Motivation & $\begin{array}{l}\text { Vocational } \\
\text { expertise }\end{array}$ & Collaboration & $\begin{array}{l}\text { Planning and } \\
\text { organising }\end{array}$ & $\begin{array}{l}\text { Under- } \\
\text { standing } \\
\text { others }\end{array}$ \\
\hline Motivation & $\mathbf{0 . 7 4 3}$ & & & & \\
Vocational expertise & 0.240 & $\mathbf{0 . 7 4 5}$ & & & $\mathbf{0 . 7 4 0}$ \\
Collaboration & 0.207 & 0.637 & 0.659 & $\mathbf{0 . 6 9 4}$ & $\mathbf{0 . 6 8 2}$ \\
Planning and organising & 0.262 & 0.718 & 0.666 & 0.738 & $\mathbf{0 . 6 8 2}$ \\
Understanding others & 0.217 & 0.756 & & & \\
\hline
\end{tabular}

The diagonal is the square root of AVE

\section{Appendix 2}

See Tables 3, 4, 5, 6 .

Table 3 Mean, standard deviation and inter-correlations for variables

\begin{tabular}{lllllllll}
\hline Variables & M & SD & \multicolumn{2}{l}{ Correlations } \\
\cline { 5 - 8 } & & & & & & & \\
& & & & 2 & 3 & 4 & 5 & 6 \\
\hline 1. Influence & .85 & .34 & 1 & & & & & \\
2. Proximity & .84 & .55 & .05 & 1 & & & & \\
3. Intrinsic motivation & 5.60 & 1.02 & $.26^{* *}$ & $.52^{* *}$ & 1 & & & \\
4. Vocational expertise & 7.49 & 1.00 & $.13^{* *}$ & $.09^{* *}$ & $.20^{* *}$ & 1 & & \\
5. Collaboration & 7.84 & .96 & $.15^{* *}$ & $.09^{* *}$ & $.18^{* *}$ & $.57^{* *}$ & 1 & \\
6. Planning and organising & 7.90 & .92 & $.12^{* *}$ & $.20^{* *}$ & $.22^{* *}$ & $.58^{* *}$ & $.54^{* *}$ & 1 \\
7. Understanding others & 7.58 & .97 & $.09^{* *}$ & $.08^{* *}$ & $.17^{* *}$ & $.59^{* *}$ & $.54^{* *}$ & $.52^{* *}$ \\
\hline
\end{tabular}

*Correlation significant at 0.05 level (2-tailed)

**Correlation significant at 0.01 level (2-tailed) 
Table 4 Direct and indirect effects of teacher interpersonal behaviour and competency levels

\begin{tabular}{llll}
\hline Paths & $\begin{array}{l}\text { Direct effect } \\
\text { without media- } \\
\text { tor }\end{array}$ & Direct effect with mediator & Indirect effect [95\% CI] \\
\hline $\begin{array}{l}\text { Proximity } \rightarrow \text { Vocational expertise } \\
\text { Proximity } \rightarrow \text { Planning and organis- }\end{array}$ & $0.097(0.00)$ & $-2.596(0.00)$ & $4.16[2.86-7.95]^{*}$ \\
$\quad$ ing & $0.218(0.00)$ & $-2.576(0.00)$ & $3.94[2.67-7.48]^{*}$ \\
$\begin{array}{l}\text { Proximity } \rightarrow \text { Understanding others } \\
\text { Proximity } \rightarrow \text { Cooperating and col- }\end{array}$ & $0.133(0.00)$ & $-2.401(0.00)$ & $3.42[2.28-6.64]^{*}$ \\
$\quad$ laborating & $0.092(0.01)$ & $-2.254(0.00)$ & $3.71[2.47-7.13]^{*}$ \\
$\begin{array}{l}\text { Influence } \rightarrow \text { Vocational expertise } \\
\text { Influence } \rightarrow \text { Planning and organis- } \\
\text { ing }\end{array}$ & $0.138(0.00)$ & $-1.124(0.00)$ & $3.25[2.10-6.40]^{*}$ \\
$\begin{array}{l}\text { Influence } \rightarrow \text { Understanding others } \\
\text { Influence } \rightarrow \text { Cooperating and col- } \\
\text { laborating }\end{array}$ & $0.098(0.01)$ & $-1.074(0.00)$ & $3.08[1.91-5.87]^{*}$ \\
\hline
\end{tabular}

Table 5 Goodness-of-fit statistics for two-group structural models

\begin{tabular}{llllllll}
\hline Model description & $\chi^{2}$ & df & $\chi^{2} / \mathrm{df}$ & CFI & TLI & RMSEA & IFI \\
\hline Unconstrained/baseline model & 1266.32 & 440 & 2.88 & 0.92 & 0.90 & 0.04 & 0.92 \\
Fully-constrained model & 1389.18 & 470 & 2.96 & 0.91 & 0.89 & 0.04 & 0.91 \\
& $\Delta \chi^{2}=69.1 ; p<0.05$ & & & & & & \\
\hline
\end{tabular}

Table 6 HCBE versus LCBE model estimates

\begin{tabular}{|c|c|c|c|c|c|c|c|c|}
\hline \multirow[t]{2}{*}{ Path estimated } & \multirow[t]{2}{*}{$\chi^{2}$} & \multirow[t]{2}{*}{$\chi^{2} / \mathrm{df}$} & \multirow[t]{2}{*}{ CFI } & \multirow[t]{2}{*}{ RMSEA } & \multicolumn{2}{|c|}{$\begin{array}{l}\text { Standardised } \\
\text { coefficient esti- } \\
\text { mate }\end{array}$} & \multirow[t]{2}{*}{$\Delta \chi^{2}(\Delta \mathrm{df}=1)$} & \multirow[t]{2}{*}{$p$} \\
\hline & & & & & HCBE & $\mathrm{LCBE}$ & & \\
\hline $\begin{array}{l}\text { Influence } \rightarrow \text { Planning and } \\
\text { organising }\end{array}$ & 1270.67 & 2.88 & 0.92 & 0.04 & -1.424 & -1.189 & 4.35 & $p<0.05$ \\
\hline Proximity $\rightarrow$ Motivation & 1286.55 & 2.92 & 0.92 & 0.04 & 0.867 & 0.874 & 20.25 & $p<0.05$ \\
\hline
\end{tabular}

Nonsignificant chi-square differences not presented 
Open Access This article is licensed under a Creative Commons Attribution 4.0 International License, which permits use, sharing, adaptation, distribution and reproduction in any medium or format, as long as you give appropriate credit to the original author(s) and the source, provide a link to the Creative Commons licence, and indicate if changes were made. The images or other third party material in this article are included in the article's Creative Commons licence, unless indicated otherwise in a credit line to the material. If material is not included in the article's Creative Commons licence and your intended use is not permitted by statutory regulation or exceeds the permitted use, you will need to obtain permission directly from the copyright holder. To view a copy of this licence, visit http://creativecommons.org/licenses/by/4.0/.

\section{References}

Ahmed, W., Minnaert, A., van de Werf, M. P. C., \& Kuyper, H. (2010). Perceived social support and early adolescents' achievement: The mediational roles of motivational beliefs and emotions. Journal of Youth and Adolescence, 39(1), 36-46.

Arbuckle, J. L. (2012). IBM SPSS Amos 21 user's guide. Amos Development Corporation.

Bentler, P. M. (1990). Comparative fit indexes in structural models. Psychological Bulletin, 107, $238-246$.

Bentler, P. M., \& Bonnet, D. G. (1980). Significance tests and goodness of fit in the analysis of covariances structures. Psychological Bulletin, 88, 588-606.

Biemans, H., Nieuwenhuis, L., Poell, R., Mulder, M., \& Wesselink, R. (2004). Competence based VET in the Netherlands: Backgrounds and pitfalls. Journal of Vocational Education and Training, 56(2), 523-538.

Billett, S. (2001). Knowing in practice: Re-conceptualising vocational expertise. Learning and Instruction, 11(6), 431-452.

Billett, S. (2003). Vocational curriculum and pedagogy: An activity theory perspective. European Educational Research Journal, 2(1), 6-19.

Bollen, K. A. (1989). Structural equations with latent variables. Willey.

Brekelmans, M. (1989). Interpersonal teacher behaviour in the classroom. [In Dutch: Interpersoonlijk gedrag van docenten in de klas]. WCC.

Brekelmans, M., Wubbels, T., \& den Brok, P. (2002). Teacher experience and the teacher-student relationship in the classroom environment. In S. C. Goh \& M. S. Khine (Eds.), Studies in educational learning environments: An international perspective (pp. 73-99). World Scientific.

Brophy, J. (1986). Teacher influences on student achievement. American Psychologist, 41, 1069-1077.

Byrne, B. M. (2016). Structural equation modeling with AMOS: Basic concepts, applications, and programming (3rd ed.). Routledge.

Cerasoli, C. P., Nicklin, J. M., \& Ford, M. T. (2014). Intrinsic motivation and extrinsic incentives jointly predict performance: A 40-year meta-analysis. Psychological Bulletin, 140(4), 980-1008. https://doi. org/10.1037/a0035661

Chen, A. (2001). A theoretical conceptualization for motivation research in physical education: An integrated perspective. Quest, 2, 35-38.

Deci, E. L. \& Ryan, R. M. (2007). SDT: Questionnaires: Intrinsic Motivation Inventory (IMI). Retrieved 8 February 2011, from http://www.psych.rochester.edu/SDT/measures/intrins.html.

Den Brok, P. (2001). Teaching and student outcomes. A study on teachers' thoughts and actions from an interpersonal and a learning activities perspective. W.C.C.

Den Brok, P., Bergen, T., Stahl, R. J., \& Brekelmans, M. (2004a). Students' perceptions of teacher control behaviours. Learning and Instruction, 14, 425-443.

Den Brok, P., Brekelmans, M., \& Wubbels, T. (2004b). Interpersonal teacher behavior and student outcomes. School Effectiveness and School Improvement, 15, 407-442.

Den Brok, P., Levy, J., Brekelmans, M., \& Wubbels, T. (2005). The effect of teacher interpersonal behaviour on students' subject-specific motivation. Journal of Classroom Interaction, 40(2), 20-33.

Den Brok, P., van Tartwijk, J., Wubbels, T., \& Veldman, I. (2010). The differential effect of the teacherstudent interpersonal relationship on student outcomes for students with different ethnic backgrounds. British Journal of Educational Psychology, 90, 199-221.

Fauth, B., Decristan, J., Decker, A. T., Büttner, G., Hardy, I., Klieme, E., et al. (2019). The effects of teacher competence on student outcomes in elementary science education: The mediating role of teaching quality. Teaching and Teacher Education. https://doi.org/10.1016/j.tate.2019.102882

Fisher, D., \& Rickards, T. (1998). Associations between teacher-student interpersonal behaviour and student attitude to mathematics. Mathematics Education Research Journal, 10(1), 3-15. 
Fornell, C., \& Larcker, D. F. (1981). Evaluating structural equation models with unobservable variables and measurement error. Journal of Marketing Research, 18(1), 39-50.

Goh, S. C., \& Fraser, B. J. (1998). Teacher interpersonal behaviour, classroom environment and student outcomes in primary mathematics in Singapore. Learning Environments Research, 1, 199-229.

Gorham, J., \& Christophel, D. M. (1992). Students' perceptions of teacher behaviors as motivating and demotivating factors in college classes. Communication Quarterly, 40(3), 239-252.

Gulikers, J. T. M., Biemans, H., \& Mulder, M. (2009). Developer, teacher, student and employer evaluations of competence-based assessment quality. Studies in Educational Evaluation, 35(2-3), 110-119.

Gulikers, J. T. M., \& Mulder, M. (2013). Modelling and measuring competencies. In S. Blömeke, O. Zlatkin-Troitschanskaia, C. Kuhn, \& J. Fege (Eds.), Modelling and measuring competencies in higher education: Tasks and challenges (pp. 231-236). Sense Publishers.

Gupta, A., \& Fisher, D. (2011). Teacher-student interaction in a technology-supported science classroom environment in relation to selected learner outcomes: An Indian study. MIER Journal of Educational Studies, Trends and Practice, 1(1), 41-59.

Hein, V. (2012). The effect of teacher behavior on students' motivation and learning outcomes: A review. Acta Kinesiologiae Universitatis Tartuensis, 18, 9-19.

Hughes, J. N., \& Cao, Q. (2018). Trajectories of teacher-student warmth and conflict at the transition to middle school: Effects on academic engagement and achievement. Journal of School Psychology, 67, 148-162. https://doi.org/10.1016/j.jsp.2017.10.003

Khaled, A. E., Gulikers, J. T. M., Tobi, H., Biemans, H. J. A., Oonk, C., \& Mulder, M. (2014). Exploring the validity and robustness of a competency self-report instrument for vocational and higher competence-based education. Journal of Psychoeducational Assessment. https://doi.org/10.1177/0734282914 523913

Kim, B., Fisher, D. L., \& Fraser, B. J. (2000). Classroom environment and teacher interpersonal behavior in secondary science classes in Korea. Evaluation and Research in Education, 14(1), 3-22.

Kouwenhoven, W., et al. (2010). Competence-based curriculum development in higher education: Some African experiences. In M. Cantrell (Ed.), Access \& expansion: Challenges for higher education improvement in developing countries (pp. 125-146). VU University Press.

Kyndt, E., Jansenns, I., Coertjens, L., Gijbels, D., Donche, V., \& van Petegem, P. (2014). Vocational education students' generic working life competencies. Vocations and Learning, 7, 365-392. https://doi.org/ 10.1007/s12186-014-9119-7

Kyriakides, L., Creemers, B. P. M., \& Antoniou, P. (2009). Teacher behaviour and student outcomes: Suggestions for research on teacher training and professional development. Teaching and Teacher Education, 25(1), 12-23.

Lapointe, J. M., Legault, F., \& Batiste, S. J. (2005). Teacher interpersonal behaviour and adolescents' motivation in mathematics: A comparison of learning disabled, average, and talented students. International Journal of Educational Research, 43, 39-54.

Lassnigg, L. (2017). Competence-based education and educational effectiveness. In M. Mulder (Ed.), Competence-based vocational and professional education: Bridging the worlds of work and education (pp. 667-694). Singapore: Springer.

Le Deist, F. D., \& Winterton, J. (2005). What is competence? Human Resource Development International, 8(1), 27-46.

MacKinnon, D. P., Fairchild, A. J., \& Fritz, M. S. (2007). Mediation analysis. Annual Review of Psychology, 58, 593-614.

Martin, D. P., \& Rimm-Kaufman, S. E. (2015). Do student self-efficacy and teacher-student interaction quality contribute to emotional and social engagement in fifth grade math? Journal of School Psychology, 53, 359-373.

Maulana, R., Opdenakker, M. C., den Brok, P., \& Bosker, R. (2011). Teacher-student interpersonal relationship in Indonesia: Profiles and importance to student motivation. Asia Pacific Journal of Education, 31, 33-49.

Maulana, R., Opdenakker, M. C., den Brok, P., \& Bosker, R. (2012). Teacher-student interpersonal behaviour in mathematics classroom in Indonesia. International Journal of Science and Mathematics Education, 10, 21-47.

Misbah, Z., Gulikers, J. T. M., Dharma, S., \& Mulder, M. (2019). Evaluating competence-based vocational education in Indonesia. Journal of Vocational Education and Training, 72, 488-515. https:// doi.org/10.1080/13636820.2019.1635634

Misbah, Z., Gulikers, J. T. M., Maulana, R., \& Mulder, M. (2015). Teacher interpersonal behaviour and student motivation in competence-based vocational education: Evidence from Indonesia. Teaching and Teacher Education, 50, 79-89. 
MoMT. (2009). Establishment of Indonesian qualification framework for subsector of food and beverage processing industry. Ministry of Manpower and Transmigration.

MoNE. (2004). Act of the Republic of Indonesia Number 20 year 2003 National Education System. The Ministry of National Education of the Republic of Indonesia, MoNE.

Mulder, M. (2014). Conceptions of professional competence. In S. Billett, C. Harteis, \& H. Gruber (Eds.), International handbook of research in professional and practice-based learning (pp. 107137). Springer.

Mulder, M. (2017). Competence theory and research: A synthesis. In M. Mulder (Ed.), Competencebased vocational and professional education: Bridging the worlds of work and education (pp. 1071-1106). Springer.

Mulder, M., \& Winterton, J. (2017). Introduction. In M. Mulder (Ed.), Competence-based vocational and professional education: Bridging the worlds of work and education (pp. 1-43). Springer.

Nuh, M. (2013, March 7). Kurikulum 2013. Harian Kompas. Retrieved 5 May 2014 from http://kemdi kbud.go.id/kemdikbud/artikel-mendikbud-kurikulum2013.

Opdenakker, M. C., Maulana, R., \& den Brok, P. (2012). Teacher-student interpersonal relationships and academic motivation within one school year: Developmental changes and linkage. School Effectiveness and School Improvement, 23(1), 95-119. https://doi.org/10.1080/09243453.2011.619198

Rawnsley, D. G. (1997). Associations between classroom learning environments, teacher interpersonal behavior and student outcomes in secondary Mathematics classrooms. Doctoral thesis, Curtin University.

Reeve, J., Bolt, E., \& Cai, Y. (1999). Autonomy-supportive teachers: How they teach and motivate students. Journal of Educational Psychology, 91(3), 537-548.

Reeve, J., \& Jang, H. (2006). What teachers say and do to support students' autonomy during a learning activity. Journal of Educational Psychology, 98(1), 209-218. https://doi.org/10.1037/0022-0663. 98.1.209

Ryan, R. M., \& Deci, E. L. (2000). Intrinsic and extrinsic motivations: Classic definitions and new directions. Contemporary Educational Psychology, 25, 54-67.

Shuell, T. J. (1996). Teaching and learning in a classroom context. In D. C. Berliner \& R. C. Calfee (Eds.), Handbook of educational psychology (pp. 726-764). Simon \& Schuster Macmillan.

Sivan, A., \& Chan, D. W. K. (2013). Teacher interpersonal behaviour and secondary students' cognitive, affective and moral outcomes in Hong Kong. Learning Environments Research, 16, 23-36. https:// doi.org/10.1007/s 10984-012-9123-5

Skinner, E. A., \& Belmont, M. J. (1993). Motivation in the classroom: Reciprocal effects of teacher behavior and student engagement across the school year. Journal of Educational Psychology, 85(4), $571-581$.

Slavin, R. E. (2008). Perspectives on evidence-based research in education - What works? Issues in synthesizing educational program evaluations. Educational Research, 37(1), 5-14. https://doi.org/10. 3102/0013189x08314117

Stroet, K., Opdenakker, M. C., \& Minnaert, A. (2015). What motivates early adolescents for school? A longitudinal analysis of associations between observed teaching and motivation. Contemporary Educational Psychology, 42, 129-140.

Sturing, L., Biemans, H. J. A., Mulder, M., \& De Bruijn, E. (2011). The nature of study programmes in vocational education: Evaluation of the model for comprehensive competence-based vocational education. Vocations and Learning, 4(3), 191-210.

Tabachnick, B., \& Fidell, L. S. (2007). Using multivariate statistics (5th ed.). Allyn \& Bacon/Pearson Education.

Taylor, G., Jungert, T., Mageau, G. A., Schattke, K., Dedic, H., Rosenfield, R., \& Koestner, R. (2014). A self-determination theory approach to predicting school achievement over time: The unique role of intrinsic motivation. Contemporary Educational Psychology, 39, 342-358.

Telli, S., den Brok, P., \& Cakiroglu, J. (2007). Teacher-student interpersonal behavior in secondary science classes in Turkey. Journal of Classroom Interaction, 42, 31-40.

Urdan, T., \& Schoenfelder, E. (2006). Classroom effects on student motivation: Goal structures, social relationships, and competence beliefs. Journal of School Psychology, 44, 331-349.

van Petegem, K., Aelterman, A., Keer, H. V., \& Rosseel, Y. (2008). The influence of student characteristics and interpersonal teacher behaviour in the classroom on students' wellbeing. Social Indicators Research, 85(2), 279-291.

van Ryzin, M. J. (2011). Protective factors at school: Reciprocal effects among adolescents' perceptions of the school environment, engagement in learning, and hope. Journal of Youth and Adolescence, 40, 1568-1580. https://doi.org/10.1007/s10964-011-9637-7 
van Uden, J. M., Ritzen, H., \& Pieters, J. M. (2014). Engaging students: The role of teachers' beliefs and interpersonal teacher behaviour in fostering student engagement in vocational education. Teaching and Teacher Education, 37, 21-32.

Ward, M., Gruppen, L., \& Regehr, G. (2002). Measuring self-assessment: Current state of the art. Advances in Health Sciences Education, 7, 63-80.

Wei, M., den Brok, P., \& Zhou, Y. (2009). Teacher interpersonal behaviour and student achievement in English as a Foreign Language classrooms in China. Learning Environments Research, 12, 157-174.

Wesselink, R. (2010). Comprehensive competence-based education. The development and use of a curriculum analysis and improvement model. Doctoral dissertation, Wageningen University and Research, the Netherlands.

Wesselink, R., Biemans, H. J. A., Gulikers, J. T. M., \& Mulder, M. (2017). Models and principles for designing competence-based curricula, teaching, learning and assessment, In M. Mulder (Ed.), Competence-based vocational and professional education. bridging the worlds of work and education (pp. 533-55). Springer.

Wesselink, R., Biemans, H. J. A., Mulder, M., \& Van der Elsen, R. (2007). Competence-based VET as seen by Dutch researchers. European Journal of Vocational Training, 40, 38-51.

Wiegel, T., Mulder, M., \& Collins, K. (2007). The concept of competence in the development of vocational education and training in selected EU member states. Journal of Vocational Education and Training, 59(1), 51-64.

Wijnia, L. (2020). Students' motivation in secondary and post-secondary education. Educational Psychology, 40(8), 913-916. https://doi.org/10.1080/01443410.2020.1813404

Wijnia, L., Loyens, S. M. M., \& Derous, E. (2011). Investigating effects of problem-based versus lecturebased learning environments on student motivation. Contemporary Educational Psychology, 36, $101-113$.

Wubbels, T., Creton, H. A., \& Hoymayers, H.P. (1985). Discipline problems of beginning teachers: Interactional teacher behaviour mapped out. Paper presented at the Annual Meeting of the American Association Research.

Wubbels, T., \& Brekelmans, M. (2005). Two decades of research on teacher-student relationships in class. International Journal of Educational Research, 43, 6-24.

Young, M. (2009). National qualification frameworks: An analytical overview. In R. Maclean \& D. Wilson (Eds.), International handbook of education for the changing world of work (pp. 2867-2880). Springer.

Publisher's Note Springer Nature remains neutral with regard to jurisdictional claims in published maps and institutional affiliations. 